\begin{tabular}{ll} 
Abstract G195 Table 1 & 'LEAD-A-Team' \\
\hline L & State you are the Leader \\
E & Stand at End of bed \\
A & Allocate roles \\
D & Describe mental model \\
-A- & Use the Algorithm \\
TEAM & Ask Team for feedback \\
\hline
\end{tabular}

\begin{tabular}{|c|c|c|c|c|c|}
\hline $\begin{array}{l}\text { Scenario } \\
\text { (25 minutes) }\end{array}$ & Role & $\begin{array}{l}\text { Faculty } \\
\text { Feedback } \\
\text { Score } \\
\text { Mean } 54 \\
\text { SD } 4.63\end{array}$ & $\begin{array}{l}\text { Self } \\
\text { Reflection } \\
\text { Score } \\
\text { Mean } 54 \\
\text { SD } 6.66\end{array}$ & $\begin{array}{l}\text { Faculty-Self } \\
\text { Score }\end{array}$ & $\begin{array}{l}\text { TeamMonitor } \\
\text { Scores (rs 0.69) }\end{array}$ \\
\hline 1 & Consultant 1 & 47 & 50 & -3 & $80.4 \%$ \\
\hline 2 & ANP 1 & 61 & 44 & +17 & $84.9 \%$ \\
\hline 3 & Consultant 2 & 60 & 51 & +9 & $80.5 \%$ \\
\hline 4 & Consultant 3 & 49 & 52 & -3 & $84.4 \%$ \\
\hline 5 & Consultant 4 & 52 & 57 & -5 & $80.2 \%$ \\
\hline 6 & ST2 & 56 & 51 & +5 & $88.5 \%$ \\
\hline 7 & ANP 2 & 53 & 66 & -13 & $91.0 \%$ \\
\hline 8 & Consultant 2 & 56 & 62 & -6 & $91.6 \%$ \\
\hline
\end{tabular}

of 72. TeamMonitor scores (Stocker et al.) were recorded by team members.

Results In 63\% of scenarios, participants gave themselves a higher m-CALM score than the observer. Observer scores did not correlate with seniority. TeamMonitor scores were averaged and converted to percentages. There was an increase of $11 \%$ from first to last scenario and a linear relationship between TeamMonitor scores and simulation course time in minutes (Spearman correlation 0.69). We acknowledge that scenario 8 was the participant's second simulation (table 2).

Conclusions These results demonstrate differences between self-perceived and observed leadership. There does not appear to be a strong relationship between seniority and perceived leadership. The team's perception of performance improves as the course progresses suggesting the LIME course was impactful.

\section{G196 THE FEAR OF LOSING A CHILD!}

${ }^{1} \mathrm{~K}$ Skehin, ${ }^{1} \mathrm{~S}$ Molloy, ${ }^{2} \mathrm{~A}$ McGrath, ${ }^{1} \mathrm{~A}$ Thompson, ${ }^{1,3} \mathrm{~T}$ Bourke, ${ }^{1} \mathrm{C}$ Flannigan. ${ }^{1}$ Paediatrics, Royal Belfast Hospital for Sick Children. Belfast, UKi ${ }^{2}$ Northern Ireland Ambulance Service, Belfast, UK; ${ }^{3}$ School of Medicine, Dentistry and Biochemical Sciences, Queen's University, Belfast, UK

\subsection{6/archdischild-2020-rcpch. 166}

Background Paramedics in Northern Ireland are expected to treat unwell children; perform life-saving interventions, in challenging surroundings with limited resources. Surprisingly, Northern Irish paramedic baseline paediatric education is minimal, and reliant on the 'Joint Colleges Ambulance Liaison Committee Clinical Guidelines' and personal experience to provide a solid foundation of knowledge. Furthermore, the
Northern Ireland Ambulance Service (NIAS) does not offer subsidised study leave. Approached by a paramedic crew, provoked by a number of tough, emotive paediatric call-outs, we conceived, designed and facilitated a collaborative, bespoke paramedic paediatric study day.

Aims

- To improve paramedic confidence in the management of unwell children.

- To provide an insight into hospital-based management of paediatric emergencies aimed to complement paramedic knowledge.

- To create a multidisciplinary forum for paramedics and paediatricians to network, improve relations and educate via a shared learning environment.

Methods

- Designed as a regional study day for NIAS members.

- Recruitment of paediatric intensivists, emergency consultants and senior paediatric trainees to facilitate lectures on emergencies; recognition, interventions and outcomes. Rotating skills stations focused on airway, cardiovascular management and an informative question and answering session.

- A simulated 'cot death' scenario to amalgamate learning objectives. A paramedic led pre-recorded out of hospital neonatal arrest call, streamed and continued in hospital with the emergency team receiving the patient. An actress played the role of the parent for authenticity.

- Responses evaluated via feedback forms.

Results This complimentary course was fully subscribed within five hours of advertisement. Fifty-five paramedics attended, 35 provided feedback; $100 \%$ felt more comfortable dealing with the unwell child after the course. Greater than $90 \%$ rated the skills station and lectures as extremely useful; simulation, validated by the actress was highlighted as 'innovative' and 'enlightening'. Further feedback read 'extremely beneficial day', 'thoroughly enjoyed and learned so much' and 'please, more of these events'. Suggested improvements included a bigger venue and more time.

Conclusion The course will run annually to facilitate regular paramedic training and enhance pre and in-hospital working relationships. The collaborative paramedic paediatric study day is a fabulous opportunity for all to progress in a shared learning environment, mutually respectful of the reality and fear of losing a child!

\section{G198(P) STUDENTS' PERCEPTIONS OF PAEDIATRICS AND THE IMPACT OF A CAREERS WORKSHOP}

CE Roberts, D Vick, JL Oakley. Children's Hospital for Wales, University Hospital of Wales, Cardiff, UK

\subsection{6/archdischild-2020-rcpch.167}

Aims Applications to specialty training are falling and retention of trainees is increasingly challenging. Clinical placements influence students' perceptions of a specialty and may impact on career choices. We evaluated medical students' views of Paediatrics before and after their placement and explored the effect of a focused Careers Workshop.

Methods A survey was distributed to medical students before $(\mathrm{n}=93)$ and after $(\mathrm{n}=74)$ their Child Heath block (Standard Group). Subsequently, a smaller group of students were invited 